\title{
The role of community energy in renewable energy use and development
}

\author{
Yoshihiro Yamamoto* \\ Department of Economics, Takasaki City University of Economics, Takasaki 370-0801, Japan
}

\begin{abstract}
As a number of researchers have observed, local communities play an important role in facilitating decentralized renewable energy (RE). Based on a literature review, this study identifies viewpoints with implications for community energy organization models that merit further investigation. First, the study identifies key features of community energy - economic and financial advantages, and community autonomy and sustainability - in the research literature. In regard to these features, the study then presents four viewpoints with implications for community energy: economic efficiency, common pool resource management, social networking, and social system context. Further research from these viewpoints will provide a better understanding of community energy and the development of RE.
\end{abstract}

\section{Introduction}

Renewable energy (RE) is increasingly being introduced worldwide due to concerns over global warming and energy security, as well as advances in RE technologies. Wind, solar, and biomass energy are commonly harnessed as RE sources.

In Japan, relative meteorological advantage and a feedin law implemented in 2012 to promote RE have contributed to widespread adoption of photovoltaic (PV) power generation (Fig. 1). In addition to rooftop installation of $\mathrm{PV}$ panels by households, private companies are also setting up large-scale $\mathrm{PV}$ systems to sell $\mathrm{PV}$ power to electric utilities under the 2012 law. These companies often collaborate with municipalities in pursuing these ventures, forming public--private partnerships in which the municipalities provide sites to companies for power generation.

Many studies have observed that communities play an important role in facilitating decentralized RE diffusion, particularly in Europe, including Germany, Denmark, the Netherlands, and the UK [2-7]. Maruyama et al. [8] also observed a number of RE projects that involve communities in Japan, and the number of such projects seems to be increasing after the devastating 2011 earthquake and subsequent nuclear disaster in Fukushima.

In this study, "community energy" refers to those RE projects in which communities are somewhat involved in terms of financial investment and managerial control. This definition, in contrast to that employed by Seyfang et al. [7], does not necessarily assume community ownership since community participation in RE projects takes a variety of

\footnotetext{
* e-mail: ysyama@tcue.ac.jp
}

organizational forms, including cooperatives, community charities, development trusts, shares owned by local community organizations, and others [3].

The RE cooperative seems like a particularly effective organizational model for community energy, as many have argued (including [9-13]). Subbarao and Lloyd [14] point out that successful projects under the Clean Development Mechanism (CDM) of the Kyoto Protocol were typically managed by cooperative ventures rather than for-profit corporations. However, while RE cooperatives have flourished in countries such as Germany and Denmark [11] (Fig. 2), they have met with less acceptance in Japan, among other countries.

This study explores community energy organizational models from four viewpoints, considering implications for the development of RE projects that merit further investigation. The exploration of viewpoints is based on a review of literature investigating the effectiveness of community energy.

The rest of the paper is organized as follows. Section 2 presents the literature review on community energy. Based on this review, Section 3 considers four viewpoints with implications for community energy. Section 4 concludes with discussion of implications for further multidisciplinary research.

\section{Literature review}

This section summarizes the main findings from research on the effectiveness of community energy. Most of these findings were based on interviews with individuals in community RE projects. In general, four salient features of community energy - economic and financial advantages, and community autonomy and sustainability - were found to contribute to the effectiveness of RE projects. 


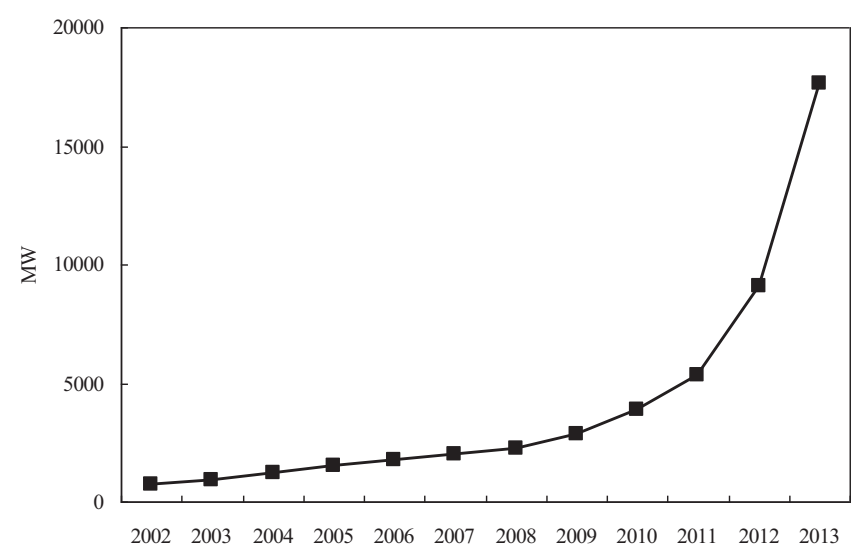

Fig. 1. Cumulative PV capacity in Japan. Data: Japan's Energy White Paper 2015 [1].

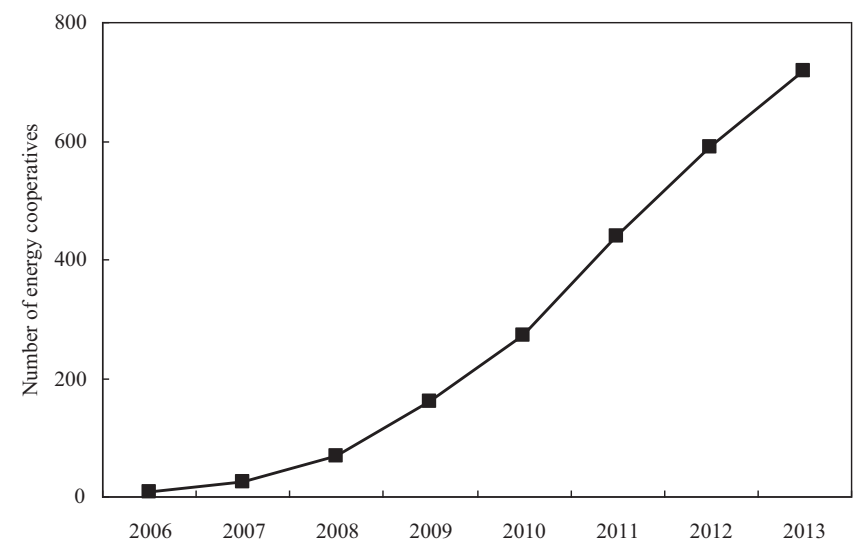

Fig. 2. Cumulative energy cooperatives in Germany. Data: DGRV Energy cooperatives survey 2014 [15].

First, community energy was found to provide economic and financial benefits to communities and local residents [3,9]. RE projects produce heat and/or power for communities, offer profitable investment opportunities, and/or provide job opportunities. Some RE projects make use of biomass produced as a by-product of agriculture, benefiting farmers in the region. These support community revitalization.

Second, community energy contributes to community autonomy and sustainability $[3,5,9,12,13]$. Local communities can participate in decision-making on $\mathrm{RE}$ projects more readily than on projects such as centralized, large-scale, power plants outside the region. Community energy may furthermore make communities less dependent on the electricity generated at such large-scale plants. Furthermore, projects enacted with and for the community enhance community revitalization and cohesion, which will strongly be connected with community spirit [12].

A number of studies have considered the role of public acceptance in community autonomy $[3,9,13,16,17]$. If a local community is involved in an RE project, then the project is more likely to be accepted by that community. If the community is not involved, local residents are more likely to resist the construction of RE facilities such as wind turbines and solar panels out of concern that such facilities will degrade the environment, produce noise, or cause other harms. This resistance is stronger, to an extent, when such projects are set up without community participation; conversely, community involvement reduces resistance to some extent. According to Subbarao and Lloyd [14], community involvement in $\mathrm{RE}$ projects under the CDM was effective in increasing public acceptance.

Finally, it should be noted that RE cooperatives are different from agricultural ones. Whereas agricultural cooperatives aim to maximize profits for member-farmers, $\mathrm{RE}$ cooperatives aim not only to yield economic benefits but also community autonomy and sustainability (see, for example, [18]).

\section{Viewpoints}

Based on the literature review of community energy research above, this section considers four viewpoints with implications for development of RE projects: economic efficiency, common pool resource management, social networking, and social system context.

\subsection{Economic efficiency}

From the viewpoint of economic efficiency, two implications emerge from the literature reviewed in Section 2. The first concerns public acceptance of RE projects. Public acceptance determines the capacity of a project, which affects generation/production efficiency, and hence the profitability of the project. However, the literature shows that while community involvement enhances public acceptance of RE, local communities do not necessarily aim at profit maximization. This trade-off must be resolved for an RE project to succeed.

Second, strong connections between RE projects and economic activity in a region may contribute to project success. For example, local farmers may produce agricultural waste, including waste from thinning and lumbering, crop harvesting, and livestock manure, that can serve as inputs for biomass energy production. If farmers both use a cooperative RE facility and are members of the cooperative, they will optimize both their own agricultural activities and the performance of the RE project. This is, precisely, an internalization of multiple businesses resulting in efficient management. RE projects incorporating such connections may positively affect the economic performance of a region.

\subsection{Common pool resource management}

The RE sources used in $\mathrm{RE}$ projects are community resources. Hence, if a company from outside of a community sets up an RE project to generate electricity to sell to the grid, local residents may feel that their resources are being appropriated without any benefit to them.

To avoid this, communities may manage the resources themselves. However, community resource management gives rise to a problem: such resources may be considered common pool resources, which are characterized by the difficulties of exclusion and subtraction of resource units. 
This characteristic may lead to a prisoner's dilemma of overuse leading to congestion, or even to the destruction of the resource [19]. Bomberg and McEwen [5] and Huybrechts and Mertens [11], among others, also mention this problem in the context of community energy.

Ostrom [20] investigated common pool resource management problems intensively. As an alternative to a prisoner's dilemma, Ostrom proposes a model in which the players "can make a binding contract to commit themselves to a cooperative strategy that they themselves will work out" ([20], p. 15). "The self-interest of those who negotiated the contract will lead them to monitor each other and to report observed infractions so that the contract is enforced" ([20], p. 17).

Whether or not this form of management is applicable to community RE resource management, and what relevance it may have to community energy, merit further investigation.

\subsection{Social networking}

I postulate that, at least in Japan, an initiator of a community RE project may be considered an opinion leader in that community, and those other participants may be considered followers of the opinion leader [21]. Previous literature, websites, and interviews I have conducted on community energy support this viewpoint to some extent.

This viewpoint has implications for the diffusion of community RE projects. Rogers [22] argues that "diffusion campaigns are more likely to be successful if change agents identify and mobilize opinion leaders" ([22], p. 388), noting that "a change agent is an individual who influences clients' innovation-decision in a direction deemed desirable by a change agency" ([22], p. 366). It follows that, to facilitate RE diffusion, it is important to provide potential opinion leaders with information on community energy.

Another kind of network may also play a role. According to Seyfang et al. [7], RE cooperatives form networks that contribute to the exchange of information on community energy.

The potential of networks to facilitate community energy also merits further investigation.

\subsection{Social system context}

As the literature review in Section 2 supports, the cooperative may be an effective organizational model for $\mathrm{RE}$ projects. However, RE cooperatives have not been widely adopted worldwide, though there are many in some countries.

Only a few RE cooperatives have been undertaken in Japan. When a group of individuals in Japan set up an RE cooperative, they establish it as a business cooperative. The business cooperative is the organizational form for small businesses that are owned by their members rather than outside investors, and that must be approved by the National Federation of Small Business Associations. RE business cooperatives are thus relatively oriented towards commerce, and in this sense, differ from RE cooperatives in
Germany and Denmark, which seem to be more oriented towards community. Furthermore, Japanese business cooperatives are less familiar to people in Japan than cooperatives in these countries.

However, neighborhood associations have long been prevalent in Japan. Japanese neighborhood associations are distinct from those in other countries. They are found nationwide (about 300,000 across Japan), and typically are characterized by high rates of citizen participation [23]. Japanese neighborhood associations support a broad range of social service activities, including cleaning and beatification, garbage disposal, festivals, fire prevention, and residential road management. Neighborhood associations have the potential to play the positive role in community energy in Japan that RE cooperatives play in other countries, although there have been no such cases to date, to my knowledge.

\section{Conclusion}

This study investigated important aspects of the role that community energy plays in decentralized RE projects. Through a literature review, the study identified key aspects of community energy - economic and financial advantages, and community autonomy and sustainability. The following four viewpoints emerged in considering the literature with regard to these aspects, each with implications for RE in community energy: economic efficiency, common pool resource management, social networking, and social system context. Further research from these viewpoints will provide a better understanding of the role of community energy in RE use and development.

The best organizational model for community energy in a given context depends on cultural, social, historical, and economic considerations [24]. Different organizational forms may prove optimal in different contexts. Developing models appropriate to given cases will facilitate diffusion of RE use.

Accordingly, further research into multiple dimensions of RE in community energy are merited, and will likely require multidisciplinary investigation.

This study was supported by a Grant-in-Aid for Scientific Research of JSPS, Grant 24560500, for which the author is grateful.

\section{References}

1. METI (Ministry of Economy, Trade and Industry of Japan), Japan's Energy White Paper 2015 (available online, in Japanese), 2015

2. M.A. Bolinger, Making European-style community wind power development work in the US, Renew. Sust. Energy Rev. 9, $556(2005)$

3. G. Walker, What are the barriers and incentives for community-owned means of energy production and use? Energy Policy 36, 4401 (2008)

4. G. Walker, P. Devine-Wright, Community renewable energy: what should it mean? Energy Policy 36, 497 (2008) 
5. E. Bomberg, N. McEwen, Mobilizing community energy, Energy Policy 51, 435 (2012)

6. C. Nolden, Governing community energy - feed-in tariffs and the development of community wind energy schemes in the United Kingdom and Germany, Energy Policy 63, 543 (2013)

7. G. Seyfang, J.J. Park, A. Smith, A thousand flowers blooming? An examination of community energy in the UK, Energy Policy 61, 977 (2013)

8. Y. Maruyama, M. Nishikido, T. Iida, The rise of community wind power in Japan: enhanced acceptance through social innovation, Energy Policy 35, 2761 (2007)

9. A. Schreuer, D. Weismeier-Sammer, Energy cooperatives and local ownership in the field of renewable energy technologies: a literature review, RiCC-research report (Research Institute for Co-operation and Co-operatives (RiCC), Vienna University of Economics and Businesses, 2010)

10. E. Viardot, The role of cooperatives in overcoming the barriers to adoption of renewable energy, Energy Policy 63, 756 (2013)

11. B. Huybrechts, S. Mertens, The relevance of the cooperative model in the field of renewable energy, Ann. Publ. Cooper. Econ. 85, 193 (2014)

12. S. Wirth, Communities matter: institutional preconditions for community renewable energy, Energy Policy 70, 236 (2014)

13. Ö. Yildiz, J. Rommel, S. Debor, L. Holstenkamp, F. Mey, J.R. Müller, J. Radtke, J. Rognli, Renewable energy cooperatives as gatekeepers or facilitators? Recent developments in Germany and a multidisciplinary research agenda, Energy Res. Soc. Sci. 6, 59 (2015)
14. S. Subbarao, B. Lloyd, Can the Clean Development Mechanism (CDM) deliver? Energy Policy 39, 1600 (2011)

15. DGRV (German Cooperative and Raiffeisen Confederation), Energy cooperatives: Findings of survey conducted by the DGRV and its member associations Spring 2014 (available online), 2014

16. C.R. Warren, M. McFadyen, Does community ownership affect public attitudes to wind energy? A case study from south-west Scotland, Land Use Policy 27, 204 (2010)

17. F.D. Musall, O. Kuik, Local acceptance of renewable energy - a case study from southeast Germany, Energy Policy 39, 3252 (2011)

18. V. Valentinov, Why are cooperatives important in agriculture? An organizational economics perspective, J. Inst. Econ. 3, 55 (2007)

19. E. Ostrom, How types of goods and property rights jointly affect collective action, J. Theor. Polit. 15, 239 (2003)

20. E. Ostrom, Governing the commons: the evolution of institutions for collective action (Cambridge University Press, New York, 1990)

21. Y. Yamamoto, Opinion leadership and willingness to pay for residential photovoltaic systems, Energy Policy 83, 185 (2015)

22. E.M. Rogers, Diffusion of innovations, 5th ed. (Free Press, New York, 2003)

23. R.J. Pekkanen, Y. Tsujinaka, H. Yamamoto, Neighborhood associations and local governance in Japan (Routledge, Oxford, 2014)

24. M.D. Tarhan, Renewable energy cooperatives: a review of demonstrated impacts and limitations, J. Entrep. Organ. Divers. 4, 104 (2015)

Cite this article as: Yoshihiro Yamamoto, The role of community energy in renewable energy use and development, Renew. Energy Environ. Sustain. 1, 18 (2016) 